\title{
Measuring Dilution and Wear for Laser Cladding of Stellite 6 Produced on a P91 Steel Substrate using Two Different Heat Inputs
}

\author{
Alain Kusmoko, Druce Dunne, Huijun Li \\ Faculty of Engineering, University of Wollongong, NSW 2522, Australia
}

\begin{abstract}
Stellite 6 was deposited by laser cladding on a P91 substrate with energy inputs of $1 \mathrm{~kW}$ (P91-1) and 1.8 $\mathrm{kW}$ (P91-1.8). The chemical compositions, microstructures and surface roughnesses of these coatings were characterized by atomic absorption spectroscopy, scanning electron microscopy and atomic force microscopy. The microhardness of the coatings was measured and the wear mechanism of the coatings was evaluated using a pin-onplate (reciprocating) wear testing machine. The results showed less cracking and pore development for Stellite 6 coatings applied to the P91 steel substrate with the lower heat input (P91-1). Further, the Stellite coating for P91-1 was significantly harder than that obtained for P91-1.8. The wear test results indicated that the weight loss for P91-1 was much lower than for P91-1.8. The surface topography data indicated that the surface roughness for P91-1 was much lower than for P91-1.8. The measurements of dilution and carbon content showed that P91-1 has lower dilution and higher concentration of carbon than P91-1.8. It is concluded that the lower hardness of the coating for P91-1.8, together with the softer underlying substrate structure, markedly reduced the wear resistance of the Stellite 6 coating and the lower hardness of the coating for P91-1.8 was due to higher level of dilution and lower concentration of carbon.
\end{abstract}

\section{Introduction}

P91 steels are high strength alloys that normally transform completely to martensite during air cooling. This means that the specification of preheating and post weld heat treating conditions is an important concern. One important issue is specification of maximum tempering temperatures which are limited by the lower critical temperature for the ferrite-to-austenite phase transformation, A1. This steel is an important steam generator material for thermal and nuclear power plants. P91 steel displays three distinct temperature regimes for the variations of tensile strength, average work hardening rate and ductility. It has the advantages of low thermal expansion, high thermal conductivity, good steam corrosion resistance and excellent creep resistance [1]. These properties improve the resistance of P91 to thermally-induced stresses and they provide a better match of properties with the lower alloy steel used throughout other components of the boilers. The higher thermal conductivity also improves heat transfer through tubing walls into cooling water. Also, P91 steels have relatively good oxidation resistance at intermediate temperatures and can exhibit high strengths up to about $600^{\circ} \mathrm{C}$. P91 is relatively resistant to tempering, and higher PWHT temperatures are generally needed to reduce hardness in weld heat-affected zones and to develop the necessary toughness in weld deposits [2].
Stellite 6 is a very versatile material that is used for hardfacing of various component parts for applications requiring wear resistance. Stellite alloys have been considered as candidate materials for surface hardening of P91 steel. The microstructure of Stellite 6 contains hard $\mathrm{M}_{7} \mathrm{C}_{3}$ carbides in interdendritic regions in both ascast and as welded conditions. Stellite alloys also contain a hard Laves phase in a softer matrix of eutectic or solid solution, which is useful for unlubricated wear conditions [3]. A little works have been done for Stellite 6 deposited on P91 steel substrate.

Surface alloying is usually done by advanced techniques such as laser cladding due to significant advantages like fast processing speed, relative cleanliness, a very high heating/cooling rate $(105 \mathrm{~K} / \mathrm{s})$ and high solidification velocity (up to a maximum of $30 \mathrm{~m} / \mathrm{s}$ ) [4]. As a result, the process has a low energy input and causes less distortion of the component than hand or arc welding. Steen and Bruck [5] have reviewed laser cladding processes. In the coaxial laser cladding process, metal powder is injected through a nozzle, which is coaxial with the laser beam. The powder absorbs laser energy and become partially melted before reaching the substrate. Part of the laser energy is also absorbed by the substrate to cause surface melting, forming a strong metallurgical bond between the substrate and the clad layer. Laser clad layers can be produced that are defect-free and result in low dilution [5].This technique has not been extensively 
studied for the development of P91 steel with different energy input.

The purpose of this study was to evaluate the sliding wear characteristics and measuring the dilution and carbon content of Stellite 6 coating materials produced by laser cladding of a P91 steel substrate with low $(1 \mathrm{~kW})$ and high $(1.8 \mathrm{~kW})$ energy inputs The sliding wear tests were carried out on flat samples in an unlubricated (dry) condition using a reciprocating wear tester with a tool steel ball. This paper discussed further on dilution measurements and estimation of carbon content of Stellite 6 coatings and the role of carbon in forming $\mathrm{Cr}_{7} \mathrm{C}_{3}$ particles to harden the deposit and contribute the increase wear resistance.

\section{Experimental methods}

\subsection{Laser cladding deposition}

Table 1. Nominal compositions (wt $\%$ ) of the P91 steel and Stellite 6 alloy [3].

\begin{tabular}{|c|c|c|c|c|c|c|c|c|}
\hline $\mathbf{( \% )}$ & $\mathbf{C o}$ & $\mathbf{C r}$ & $\mathbf{F e}$ & $\mathbf{W}$ & $\mathbf{N i}$ & $\mathbf{C}$ & $\mathbf{S i}$ & $\mathbf{M n}$ \\
\hline S 6 & 60 & 27 & 2.5 & 5 & 2.5 & 1 & 1 & 1 \\
\hline P91 & & 9.0 & & & $\begin{array}{c}0.0 \\
8\end{array}$ & $\begin{array}{c}0.0 \\
9\end{array}$ & $\begin{array}{c}0.4 \\
5\end{array}$ & $\begin{array}{c}0.4 \\
6\end{array}$ \\
\hline (\%) & P & S & Mo & V & Al & Ti & Nb & B \\
\hline S 6 & & & & & & & & \\
\hline P91 & & & $\begin{array}{c}0.9 \\
6\end{array}$ & $\begin{array}{c}0.1 \\
9\end{array}$ & $\begin{array}{c}0.0 \\
8\end{array}$ & & & \\
& & & 6 & & \\
\hline
\end{tabular}

The laser cladding process of P91 steel substrates with Stellite 6 was carried out by a commercial coating manufacturing company using $1 \mathrm{~kW}$ and $1.8 \mathrm{~kW}$ energy input. The initial coating thickness as received was about $0.35 \mathrm{~mm}$ for both energy inputs. Table 1 shows the nominal compositions of the P91 steel and the Stellite 6 alloy.

\subsection{Characterisation of stellite coated samples}

The microhardness measurements were made at intervals of $0.05 \mathrm{~mm}$ through the coating thickness using a Leco M-400-H1 hardness testing machine with a load of $300 \mathrm{~g}$. The samples were then etched in a mixed acid solution to reveal the microstructure of the Stellite 6 coating. Subsequently, coatings were studied using a Leica DMRM optical microscope.

\subsection{Wear testing}

Wear testing was carried out using a pin-on-plate (reciprocating) mode with a $6 \mathrm{~mm}$ tool steel ball as the pin. During operation, the ball remained stationary while the flat specimen moved in a linear, back and forth sliding motion, under a prescribed set of conditions.

Since the aim of the work was to examine the wear of Stellite 6 coating materials, it was necessary to grind and polish the flat specimens (coatings) to the required surface finish for the wear test. The coatings were about
$0.3-0.4 \mathrm{~mm}$ thick and approximately $0.05 \mathrm{~mm}$ of the coating was removed.

Prior to carrying out the wear tests, the test specimens were weighed to an accuracy of $0.0001 \mathrm{~g}$. The flat specimen was then screwed firmly in place on the base of the wear tester. After the test was complete, wear debris was removed from the sample, which was then washed in alcohol, dried, and reweighed.

The tool steel ball was also washed in alcohol, dried and weighed to an accuracy of $0.0001 \mathrm{~g}$ at the start of each test and at the same time as the flat specimen. The ball was re-weighed after testing but, as the weight of the steel ball did not change significantly, it was not considered in assessing the wear damage.

The test speed, number of cycles and test duration were held constant: $50 \mathrm{rpm}, 10,000$ cycles and 200 minutes. The various tests conducted are: Test\# 1, P91-1 with applied load of $2 \mathrm{~kg}$; Test\# 2, P91-1.8 with applied load of $2 \mathrm{~kg}$; Test\# 3, P91-1 with applied load of $5 \mathrm{~kg}$; Test\# 4, P91-1.8 with applied load of $5 \mathrm{~kg}$.

\subsection{Examination of wear damage and topography.}

In order to study the effect of laser energy input and the applied load during wear testing on the wear track, the surfaces of the samples from Tests\# 1-4 were examined after testing using a S440 scanning electron microscope (SEM) operating at $20 \mathrm{kV}$ and using Atomic Force Microscopy (Veeco) with a scan size of $50 \mu$ and scan rate of $1 \mathrm{~Hz}$.

\subsection{Measurements of dilution and estimation C content}

A measured compositions of Stellite 6 coatings has been conducted using AAS (Atomic Absorption Spectroscopy) to determine the chemical analyses present using two different laser power ( $1 \mathrm{~kW}$ and $1.8 \mathrm{~kW})$. However, the $\mathrm{C}$ content was not detected. Therefore it was necessary to estimate the $\mathrm{C}$ content by calculating dilution. The method of calculation is shown in Fig. 1.

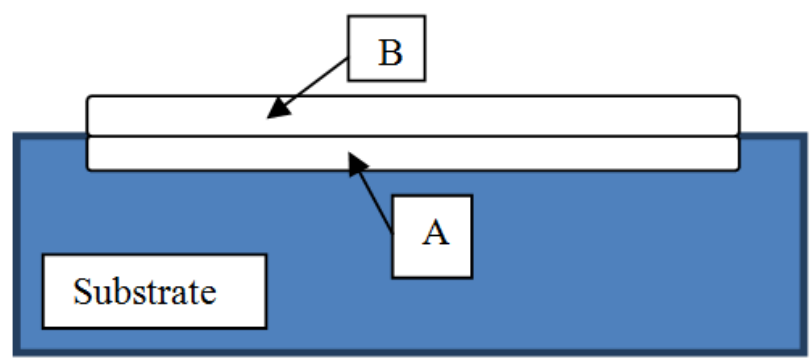

Figure 1. Schematic diagram showing the clad layer, which consists of two parts: added Stellite 6 alloy (region B) and melted base plate (region A). The dilution D of the Stellite alloy is given by $\mathrm{A} /(\mathrm{A}+\mathrm{B})[6]$.

If the $\mathrm{C}$ content (wt $\%$ ) of the substrate is given by $[\mathrm{C}]_{\mathrm{BM}}$ and the $\mathrm{C}$ content (wt\%) of the Stellite 6 is $[\mathrm{C}]_{\mathrm{S}}$ then the estimated $\mathrm{C}$ content of the weld deposit $[\mathrm{C}]_{\mathrm{WD}}$ is given as follows: 


$$
[\mathrm{C}]_{\mathrm{WD}}=\mathrm{D} \times[C]_{\mathrm{BM}}+(1-\mathrm{D}) \mathrm{x}[\mathrm{C}]_{\mathrm{S}}
$$

The nominal carbon content $[\mathrm{C}]_{\mathrm{S}}$ of the Stellite 6 alloy is $1.0 \mathrm{wt} \% \mathrm{C}$. Therefore, $[\mathrm{C}]_{\mathrm{WD}}=\mathrm{D} \times[\mathrm{C}]_{\mathrm{BM}}+(1-\mathrm{D})$.

\section{Results}

\subsection{Coating compositions}

The compositions of the Stellite 6 coatings were determined by AAS (Atomic Absorption Spectroscopy), see Table 2. Table 2 shows that the two chemical analyses (P91-1 and P91-1.8) of the coatings were similar, but there were some differences in alloy content of the coatings. The most significant differences were the lower $\mathrm{Fe}$ and Mn contents of the coating for P91-1, consistent with a lower level of dilution of the Stellite coating by the substrate.

\subsection{Scanning Electron Microscopy (SEM) of deposit coating cross-sections}

The coatings on the P91 steel substrate had a cellulardendritic appearance. The higher heat input of $1.8 \mathrm{~kW}$ produced a coarser cellular-dendritic structure, see Fig. 2 (a-b).

(a)

(b)

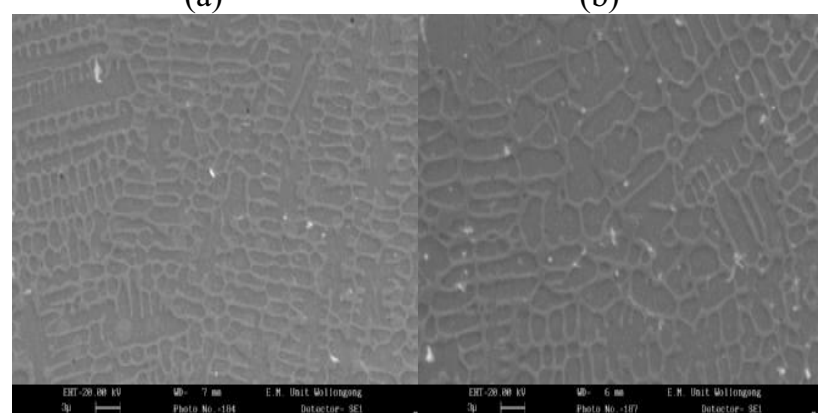

Figure 2. SEM micrograph of cross-sections of the Stellite 6 layer deposited on (a) P91-1, (b) P91-1.8.

\subsection{Microhardness testing of coating cross- sections}

Microhardness profiles for the Stellite 6 weld samples is shown in Fig. 3. For the coating deposited at $1 \mathrm{~kW}$, the coating hardness was about $550 \mathrm{HV}$ compared with 500 $\mathrm{HV}$ for $1.8 \mathrm{~kW}$. The HAZ hardness was generally lower than that of the coating, but higher than the substrate. The hardness of the unaffected substrate was about $225 \mathrm{HV}$.

\subsection{Wear testing}

Tests\# 1-2 were conducted using an applied load of $2 \mathrm{~kg}$. It was found that the deposit for P91-1 wore substantially less, while the deposit for P91-1.8 showed significant wear with deep grooves. The effect of a higher load (5 $\mathrm{kg}$ ), Test\# 3-4, was generally similar to that for Tests\# 12, see Fig. 4 (a-b).

\subsection{Mass loss}

Table 3 shows the weight loss measurements for the Stellite coated samples. It can be seen in Table 3 (Tests\# 1-4) that the weight loss increased with load and was higher for P91-1.8.

Table 2. Measured compositions of the Stellite 6 coatings.

\begin{tabular}{|c|c|c|}
\hline$(w t \%)$ & P91-1 & P91-1.8 \\
\hline $\mathbf{P}$ & 0.23 & 0.25 \\
\hline Mn & 0.33 & 0.40 \\
\hline $\mathbf{S i}$ & 0.57 & 0.59 \\
\hline $\mathrm{Ni}$ & 2.40 & 2.00 \\
\hline $\mathrm{Cr}$ & 29.25 & 28.40 \\
\hline Mo & 0.23 & 0.13 \\
\hline $\mathrm{Cu}$ & 0.011 & 0.039 \\
\hline $\mathbf{N b}$ & 0.02 & $<0.01$ \\
\hline Ti & 0.02 & 0.02 \\
\hline V & 0.028 & 0.024 \\
\hline $\mathrm{Fe}$ & 6.2 & 8.2 \\
\hline W & 4.1 & 3.9 \\
\hline Co & 54.0 & 53.1 \\
\hline
\end{tabular}

Table 3. Weight loss for Stellite coatings deposited at a power input of $1 \mathrm{~kW}$ and $1.8 \mathrm{~kW}$.

\begin{tabular}{|c|c|c|}
\hline Loads (kg) & P91-1 (g) & P91-1.8 (g) \\
\hline 2 & 0.00488 & 0.00496 \\
\hline 5 & 0.01962 & 0.02736 \\
\hline
\end{tabular}




\subsection{Characterisation of wear}

In order to study the effect of load on the wear track, Stellite coated samples were examined at the completion of the wear test by scanning electron microscopy and atomic force microscopy to establish the nature of wear.

The worn surface of P91-1, Fig. 5 (a), is smooth compared to the P91-1.8 surface which was more porous and showed greater surface roughness. The effect of a higher load $(5 \mathrm{~kg})$ at $1.8 \mathrm{~kW}$ heat input is illustrated by Fig. 5 (b).

The surface roughness of P91-1, Fig. 6 (a), has $R_{a}$ of $74.284 \mathrm{~nm}$, while for the higher heat input, P91-1.8 has a value of $89.237 \mathrm{~nm}$, Fig. 6 (b).

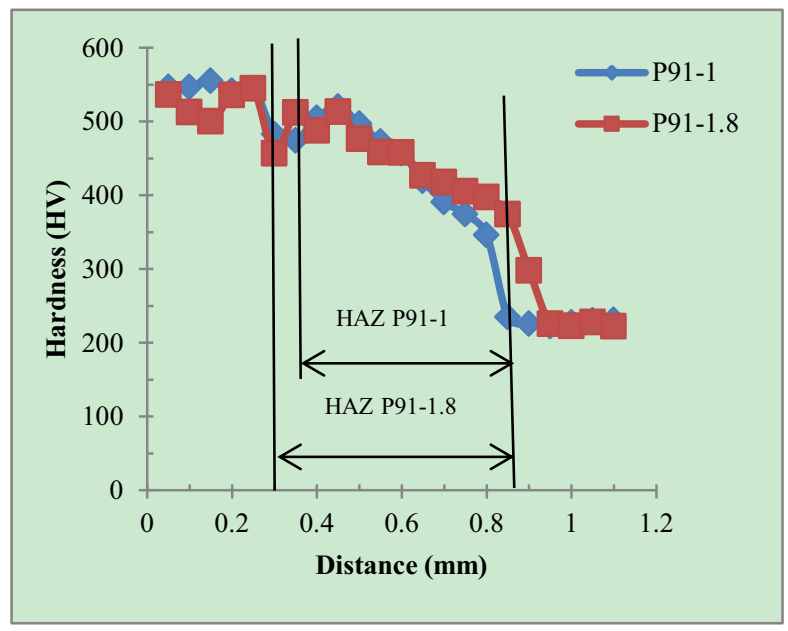

Figure 3. Graph of hardness profiles with distance from the coating surface for Stellite 6 deposited on P91 steel.

(a)

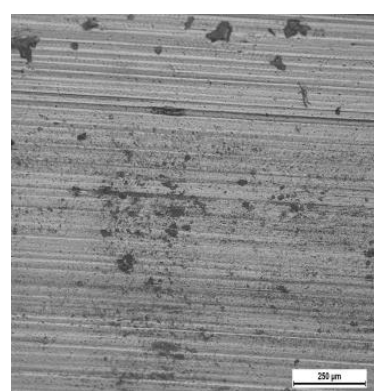

Figure 4. Optical micrographs showing wear tracks at a load of (a) $2 \mathrm{~kg}$ for P91-1, (b) $5 \mathrm{~kg}$ for P91-1.8.

(a)

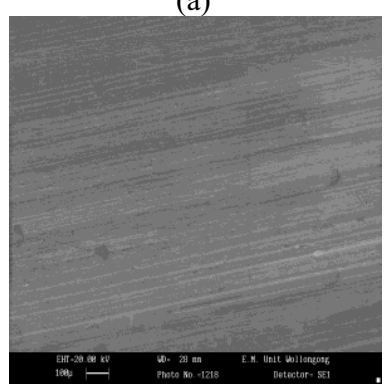

Figure 5. SEM micrograph of worn surface tested at a load of (a) $2 \mathrm{~kg}$ for P91-1, (b) $5 \mathrm{~kg}$ for P91-1.8.

\section{3,7 Dilution measurements and estimation of carbon content}

In order to estimate the carbon content of the Stellite 6 coatings as the carbon was not determined in Table 2, it was necessary to measure the dilution shown in Fig. 1, subsequently the $\mathrm{C}$ content was estimated. Tables 4 and 5 show the estimation of dilution and carbon content of Stellite 6 coatings. (a)

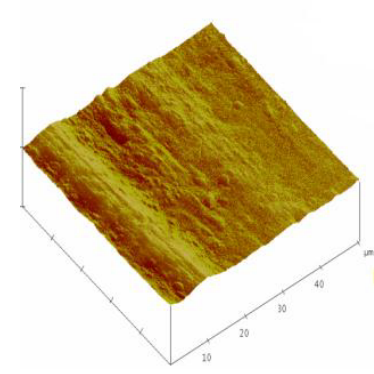

(b)

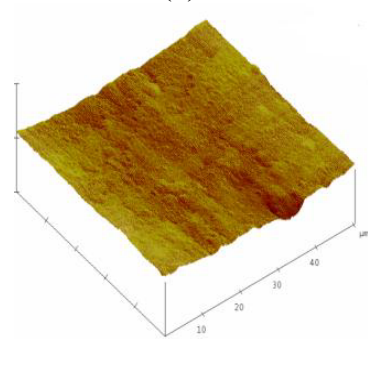

Figure 6. AFM micrographs of surface roughness tested at a load of $2 \mathrm{~kg}$ for (a) P91-1 and (b) P91-1.8.

Table 4. Measurements of dilution of the Stellite 6 coatings.

\begin{tabular}{|c|c|c|c|}
\hline & $\begin{array}{c}\text { Area of A } \\
\left(\boldsymbol{\mu \mathbf { m } ^ { 2 } )}\right.\end{array}$ & $\begin{array}{c}\text { Area of B } \\
\left(\boldsymbol{\mu \mathbf { m } ^ { 2 } )}\right.\end{array}$ & $\begin{array}{c}\text { Dilution D } \\
(\mathbf{w t} \%)\end{array}$ \\
\hline P91-1 & 69332.749 & 805707.663 & 0.1292 \\
\hline P91-1.8 & 115010.680 & 1157493.983 & 0.1904 \\
\hline
\end{tabular}

Table 5. Estimation of C content of the Stellite 6 coatings.

\begin{tabular}{|c|c|c|c|c|}
\hline & $\begin{array}{c}{[\mathbf{C}]_{\text {BM }}} \\
(\mathbf{w t \%})\end{array}$ & $\begin{array}{c}{[\mathbf{C}]_{\mathbf{s}}} \\
\mathbf{( w t \% )}\end{array}$ & $\begin{array}{c}\text { Dilution D } \\
\mathbf{( w t \% )}\end{array}$ & $\begin{array}{c}{[\mathbf{C}]_{\mathbf{W D}}} \\
\mathbf{( w t \% )}\end{array}$ \\
\hline P91-1 & 0.09 & 1.00 & 0.1292 & 0.882 \\
\hline P91-1.8 & 0.09 & 1.00 & 0.1904 & 0.827 \\
\hline
\end{tabular}

\section{Discussion}

The comparative tests conducted for laser clad P91 steel substrate showed that the weight loss was lower for coated samples deposited at a heat input of $1 \mathrm{~kW}$ (P91-1). The amount of wear (mass loss) of the Stellite coated samples was greater for the tests conducted on coatings 
deposited with $1.8 \mathrm{~kW}$ than for those deposited at $1 \mathrm{~kW}$, as shown in Table 3.

For deposits produced at $1 \mathrm{~kW}$, the weight loss increased by a factor of about 4 with increasing test load up to $5 \mathrm{~kg}$, but for the higher heat input the rate of weight loss strongly increased by a factor of about 7 with increasing load. It is likely that the greater incidence of microcracks and porosity observed after wear testing of P91-1.8 samples is due in part to the substrate, particularly to the HAZ, being softer and less rigid [7].

The higher wear rate for the P91-1.8 Stellite coated samples is also consistent with the lower surface hardness of approximately $500 \mathrm{HV}$ compared with $550 \mathrm{HV}$ for the P91-1 Stellite coated samples, as shown in Fig. 3. Acceleration of the wear rate is therefore likely for the Stellite coating P91-1.8 as the wear grooves penetrate the coating [7].

As Table 2 describes, the Stellite composition was modified by the substrate. This change occurred by melting of the substrate and mixing with the deposited alloy (dilution). Because of substrate dilution, the coating produced on the P91 steel substrate showed higher $\mathrm{Cr}, \mathrm{Fe}$, $\mathrm{Mo}, \mathrm{V}$ and $\mathrm{Nb}$ contents than those of the nominal Stellite 6 composition given in Table 1, while the $\mathrm{Co}, \mathrm{Ni}, \mathrm{Mn}, \mathrm{Si}$ and $\mathrm{W}$ contents were reduced (Table 2 ).

Although the compositions of the two coatings are similar, there are significantly lower $\mathrm{Fe}$ and $\mathrm{Mn}$ contents for the coating deposited at $1 \mathrm{~kW}$, consistent with a lower level of dilution, hence promoting the formation of $\mathrm{Cr}_{7} \mathrm{C}_{3}$ particles and hardening of the deposit [8]. The deposit on P91-1 was about $50 \mathrm{HV}$ points higher than for the coating on P91-1.8 (Fig. 3), this difference would be expected to substantially contribute the increase wear resistance [8]. The underlying HAZ was also marginally harder for the lower heat input (Fig. 3), providing a more rigid layer beneath the coating [8].

The higher level of dilution for P91-1.8 Stellite coated samples, Table 4 are consistent with higher wear rate, Table 3 and lower surface hardness, Fig. 3 of approximately $500 \mathrm{HV}$ compared with $550 \mathrm{HV}$ for the P91-1 Stellite coated samples, indicating that P91 has strong carbide formers such as $\mathrm{Cr}, \mathrm{V}$ and $\mathrm{Nb}$ to produce higher hardness on P91-1 Stellite coated samples [7, 8].

As Table 5 shows, the carbon content of weld deposit for the P91-1 Stellite coated samples was higher by a factor about $1.0665 \%$ than P91-1.8 Stellite coated samples, suggesting the higher of $\mathrm{C}$ content consistent with a lower level of dilution, Table 4 , hence promoting the carbide formation of $\mathrm{Cr}_{7} \mathrm{C}_{3}$ particles and to harden the deposit, Fig. 3, thus producing higher wear resistance [9].

\section{Summary and conclusions}

The present study compared the wear behaviour of Stellite 6 under reciprocating wear conditions as laser clad deposits on two different heat inputs $(1.0 \mathrm{~kW}$ and 1.8 $\mathrm{kW})$ of P91 steel. The coating composition was slightly different in the two cases because of differential dilution by the substrate. The compositional differences combined with different cooling rates after deposition resulted in substantially different coating hardnesses. The coating on
P91-1 had a hardness of approximately $550 \mathrm{HV}$, whereas the coating on P91-1.8 had a hardness of approximately $500 \mathrm{HV}$. The tests were carried out unlubricated, using loads of 2 and $5 \mathrm{~kg}$ and a speed of $50 \mathrm{rpm}$ for 10000 revolutions.

The results described that the rate of weight loss and the total weight loss were higher for the higher load and also for the higher heat input. The wear rate was lower for P91-1 coated samples, with less cracking and pore development in the Stellite 6 coatings. The measurements of dilution showed that the level of dilution was higher for the higher heat input and the carbon content estimation also indicated that carbon content was higher for the lower heat input.

It is concluded that the deposit obtained at $1 \mathrm{~kW}$ was harder because of compositional, microstructural, surface topography and level of dilution differences; and the harder coating resulted in the higher wear resistance due to higher $\mathrm{C}$ content of weld deposit to form carbide $\left(\mathrm{Cr}_{7} \mathrm{C}_{3}\right.$ particles $)$ to harden the deposit than the Stellite 6 coating deposited at the higher heat input of $1.8 \mathrm{~kW}$.

\section{Acknowledgements}

The authors would like to thank to Laser Bond and Jarvie Engineering companies who have provided the laser cladding.process for this research.

\section{References}

1. M. El-Azim, O. El-Desoky, H. Ruoff, F. Kauffmann, and E. Roos, Creep Fracture Mechanism in Welded Joints of P91 Steel, J. Ins. Mat. Min. and Mig.. 29, 1027-1033 (2013)

2. E. Samuel and B. Choudhury, Tensile Work Hardening Behaviour of P91 Steel, J. Mat. Sci. and Eng. A, 528, 7827-7830 (2011)

3. Tribology T-900 Technical Data, Stellite Coating Division, Deloro Stellite Company, Goshen, Indiana (2002)

4. J. D. Majumdar, A. Kumar, and L. Li, Direct Laser Cladding of SIC Disperse AISI 316L Stainless Steel, J. Trib. Int, 42, 750-753 (2009)

5. G. J. Bruck, High Power Laser Beam Cladding, J. Min. Met. \& Mat Sco, 39, 10-23 (1987)

6. F. Meriaudeau, F. Truchetet, D. Grevey and A. B. Vannes, Laser Cladding Process and Image Processing, J. Laser in Eng, 6, 161-187 (1997)

7. T. Lolla, J. Siefert, S. S. Babu and D. Gand, Delamination Failures of Stellite Hardfacing in Power Plants: A Microstructural Characterisation Study, J. Man. Onl, 19, 476-486 (2014)

8. A. Kusmoko, D. Dunne, H. Li and D. Nolan, 'Effect of Two Different Energy Inputs for Laser Cladding of Stellite 6 on P91 and P22 Steel Substrates, J. Proc. Mat. Sci, 6, 26-36 (2014)

9. A. Kusmoko, The Effect of Heat Input for Stellite 6 Deposited on High Strength Steel Substrates by Laser Cladding, $P h D$ Thesis, The University of Wolongong (2016) 